\title{
Is total en bloc sacrectomy using a posterior-only approach feasible and safe for patients with malignant sacral tumors?
}

\author{
Jie Zang, MD, Wei Guo, MD, PhD, Rongli Yang, MD, Xiaodong Tang, MD, and Dasen Li, MD \\ Musculoskeletal Tumor Center, People's Hospital, Peking University, Beijing, China
}

OBJECT In this study the authors' aim was to describe their experience with total en bloc sacrectomy using a posterioronly approach and to assess the outcome of patients with malignant sacral tumors who underwent this procedure at their center.

\begin{abstract}
METHODS The authors identified and retrospectively reviewed the records of 10 patients with malignant sacral tumors who underwent a total en bloc sacrectomy via a single posterior approach at their center. The pathological diagnosis was chordoma in 4 patients, chondrosarcoma in 1, osteosarcoma in 1, malignant schwannoma in 1, malignant giant cell tumor in 1, and Ewing's sarcoma in 2. Radiological examination revealed that the tumor involved S1-5 in 7 patients, S1-4 in 1, S1-3 in 1, and S1-2 in 1 .

RESULTS All 10 patients were stable during the perioperative period. The mean surgery duration was 282 minutes (range 250-310 minutes). The median estimated blood loss was $2595 \mathrm{ml}$ (range 1500-3200 ml). All patients were followed up for 13-29 months (mean 22 months). Two patients had a local recurrence. Two patients died of disease, 1 patient was alive with disease, and 7 patients were alive without evidence of disease. Among the 8 surviving patients, 6 were able to walk without assistive devices, and 2 were able to walk with crutches. The total complication rate was $40 \%$ (4 of 10). Wound complications (deep infection and wound healing problems) occurred in 3 patients, and a distal deep vein thrombosis occurred in 1 patient.
\end{abstract}

CONCLUSIONS Total en bloc sacrectomy using a posterior-only approach is feasible and safe in selected patients and is an important procedure for the treatment of primary malignant tumor involving the entire sacrum or only the top portion.

http://thejns.org/doi/abs/10.3171/2015.1.SPINE14237

KEY WORDS total en bloc sacrectomy; sacral tumor; posterior-only approach; oncology

$\mathrm{P}$ RIMARY neoplasms of the sacrum are rare. The most common primary tumors include chordoma, chondrosarcoma, and giant cell tumor, which are resistant to conventional radiation therapy and chemotherapy. ${ }^{13,29}$ The risk of local recurrence is relatively high when a malignant tumor or an aggressive benign tumor is excised with an intralesional margin. ${ }^{6,23,44}$ To reduce the risk of local recurrence and provide a cure for these patients, an en bloc sacrectomy with an adequate tumor-free margin is necessary.

Sacral tumor resection represents a major challenge for oncology surgeons due to the complex anatomy, the difficulty in achieving safe margins in this location, and massive bleeding during the operation. ${ }^{17,37,42}$ Primary malignant tumors or benign aggressive tumors involving the upper sacrum are even more complicated, as the entire sacrum must be resected en bloc to achieve better local control. Total en bloc sacrectomy is traditionally performed using a combined anterior-posterior approach in 1 or 2 stages. ${ }^{11,15,17,19,42,45}$ The bilateral internal iliac artery and branches of the iliac vessels are first separated, and then the branches are ligated and dissected from the sacrum. Next, the soft tissue anterior to the tumor is detached, and the intervertebral disc between L-5 and S-1 is removed through an anterior approach with open surgery or laparoscopic surgery. The entire sacrum is subsequently removed using 
a posterior approach. This combined approach requires a long surgical duration and causes excessive trauma to the patient. To decrease the surgical duration, minimize the trauma of surgery, and decrease the surgical risk, total en bloc sacrectomy has been performed using a posterior-only approach ${ }^{25}$ This approach is not commonly performed, however, because iliac osteotomy and vital vessel management are difficult.

The aim of the present study was to describe our experience with total en bloc sacrectomy using a posterioronly approach and to assess the outcome of patients with malignant sacral tumors who underwent this procedure in our center.

\section{Methods}

After obtaining research ethics board approval for the study, we identified and retrospectively reviewed the records of 11 patients with malignant sacral tumors who underwent a total en bloc sacrectomy via a single posterior approach at the Musculoskeletal Tumor Center of Peking University People's Hospital from July 2011 to July 2013. One patient was excluded because the follow-up time was less than 12 months. This left 10 patients $(5$ men and 5 women; mean age 35 years, range 12-66 years) for the study. The pathological diagnosis was chordoma in 4 patients, chondrosarcoma in 1, osteosarcoma in 1, malignant schwannoma in 1, malignant giant cell tumor in 1, and Ewing's sarcoma in 2 (Table 1). The main symptom in these patients was sacrococcygeal pain radiating to the buttocks and lower limbs, similar to sciatica pain caused by lumbar disc protrusion. In addition to the symptom of pain, the patients had problems with defecation and urination. The tumor, which usually protruded forward and pushed against the rectum, was easily palpable by digital rectal examination in all patients. A preoperative biopsy is necessary for patients with sacral tumors. For benign lesions, intralesional curettage is the appropriate choice to achieve local control. For primary malignant sacral tumors, wide resection provides the best chance for local control and should be the surgery of choice. Patients with osteosarcoma and Ewing's sarcoma received neoadjuvant chemotherapy before local treatment. The senior surgeons (W.G., R.Y., and X.T.) performed a preoperative CT-guided core biopsy in 9 patients, and the biopsy tracks for all 9 patients were removed with the sacral tumor to avoid tumor dissemination resulting from biopsy. The remaining patient (Case 9), who had previously undergone surgery at other hospitals, had local recurrence and was transferred to our hospital. Radiological examination revealed that the tumor involved S1-5 in 7 patients, S1-4 in 1, S1-3 in 1, and S1-2 in 1. According to the staging system of the Musculoskeletal Tumor Society ${ }^{12} 4$ primary malignant tumors were classified as Stage IB, 5 as Stage IIB, and 1 as Stage III. Surgical margins were determined by surgeons and pathologists. We classified the margins as either "inadequate" (intraoperative tumor rupture or positive margin at pathological analysis) or "adequate" (neither intraoperative tumor rupture nor positive margin at pathological analysis). All 10 patients agreed to total sacrectomy, and the goal of surgery was to achieve an adequate margin. The operations were performed by the senior surgeons

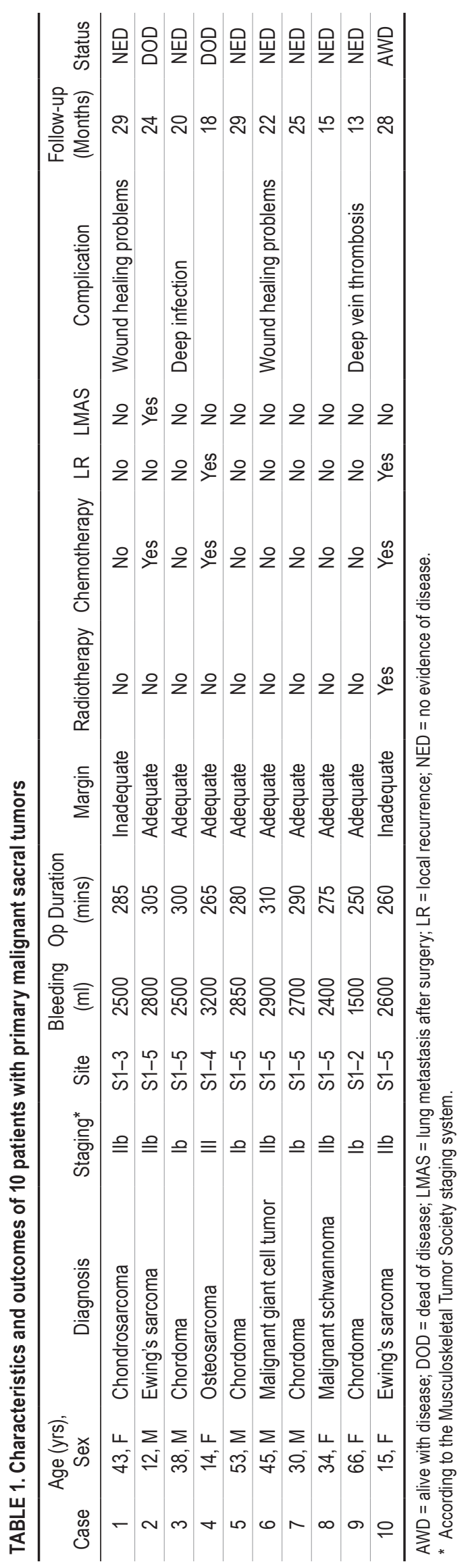


(W.G., R.Y., and X.T.). The patient with osteosarcoma and the 2 patients with Ewing's sarcoma underwent additional adjuvant chemotherapy. Complications, including surgery-related complications and mechanical failures of the instrumentation fixation, were determined at the final follow-up. A major complication was defined as one that required additional surgical procedures. A minor complication was defined as one that required nonsurgical management. The 5-year survival rate of the patients was estimated by Kaplan-Meier survival analysis using the SPSS software package (SPSS Inc.).

\section{Surgical Technique}

Indications for total en bloc sacrectomy using a posterior-only approach in our series were as follows: 1) primary malignant sacral tumor involving at least $\mathrm{S} 1-2 ; 2$ ) tumor not involving the internal iliac vessels and bowel, based on imaging studies and digital rectal examination; and 3) recurrent sacral tumor in patients who had not previously undergone an anterior procedure.

Before surgery, intraarterial embolization was performed in the radiation department via femoral access to selectively embolize the main arteries feeding the sacral tumor. The arteries were embolized according to the blood supply to the sacrum, resulting in occlusion of the lateral sacral, iliolumbar, and middle sacral arteries. The bilateral internal iliac arteries were not routinely embolized. Immediately after embolization, the patient was taken to the operating room, placed under general anesthesia, and placed supine, and a balloon was inserted into the abdominal artery via femoral access. The aortic balloon was inflated during the tumor resection. We first described this technique in $2010,{ }^{38}$ and it may decrease the total and intraoperative blood loss volumes in patients treated with sacral tumor surgery who require extensive dissection. The patient was then placed prone.

An inverted $\mathrm{Y}$ incision, comprising a posterior longitudinal midline incision in the lumbosacral region with the distal end above the sacrococcygeal joint, and 2 other incisions starting above the sacrococcygeal joint and running along the fibers of the gluteus maximus muscle, were made to expose the posterior aspect of the sacrum and the adjacent ilium. The parasacral muscles, the gluteus maximus muscles, and the gluteus medius muscles were dissected away, and the L4-5 spinal process and lamina, posterior cortex of the sacrum, and back aspect of the bilateral ilium were exposed. Four transpedicle screws were placed into the L-4 and L-5 pedicles before resecting the sacrum. After exposure of the posterior sacrum, the anterior sacrum was separated from the surrounding tissue. The rectum could be visualized from the posterior approach after resecting the sacrospinous ligament, the sacrotuberous ligament, and the sacrococcygeal ligament. The rectum was bluntly dissected from the tumor up to the S-1 level, and gauze was packed into the space between the rectum and sacrum to position the rectum forward so that the integrity of the rectum was carefully maintained during the dissection (Fig. 1).

The dura sac and both sides of the L-5 nerve roots were identified and preserved through resection of the lamina above the tumor and inferior articular process of L-5. The dura sac below L-5 was ligated and divided. The L5-S1 disc was removed as thoroughly as possible using a posterior approach. The bilateral transverse processes of L-5 were removed to facilitate blunt finger dissection from the upper and lower edges of the sacroiliac joints. The lumbosacral trunk was identified, and gauze was packed into the space in front of the sacroiliac joints to keep the lumbosacral trunks and internal iliac vessels away from the iliac osteotomy lines so that the integrity of the lumbosacral trunks and internal iliac vessels was carefully maintained during the osteotomy. The upper and lower edges of the sacroiliac joint were identified.

A silicone tube was introduced through the anterior space of the sacroiliac joint, so that a wire saw could be passed through to cut both sides of the iliac bone along the outer edge of the sacroiliac joint to achieve an adequate margin, and the sciatic nerves and gluteal vessels were well protected. After osteotomy of the bilateral ilium, the sacrum was mobilized. The iliac vessels, lumbosacral trunks, sacral nerves, and rectum could be visualized by lifting the sacrum. The branches of the iliac vessels were separated and ligated through the retroperitoneal space to mobilize the bilateral iliac vessels from the sacrum, and the middle sacral artery was identified, ligated, and divided. Soft tissue anterior to the tumor was separated, and the sacral nerve roots were cut. The remaining part of the L5-S1 disc was removed. The entire sacrum and bilateral partial ilium were then removed (Fig. 2).

After total sacrectomy, 2 transpedicle screws were placed into each side of the ilium, and 2 or 4 rods were used to connect the screws between the lumbar area and the ilium. A fibular bone graft between L-5 and the ilium, combined with instrumentation fixation, was performed in 3 young patients.

\section{Postoperative Care}

Silicone drainage tubes were inserted for wound drainage and were kept in place until the daily drainage volume was less than $30 \mathrm{ml}$. Systemic antibiotics were administered until the drainage tube was removed. Radiotherapy was administered to the patient with Ewing's sarcoma if an inadequate surgical margin was achieved. Patients were allowed to perform active exercises of the low extremities in bed postoperatively. The patients were allowed to stand with a lumbosacral orthosis and walk with the aid of crutches or a walker 4-6 weeks after surgery. They were examined every 3 months for the first 2 years, then every 6 months between 2 and 5 years, and annually thereafter.

\section{Results}

\section{Surgical and Oncological Results}

All 10 patients were stable during the perioperative period. The mean surgery duration was 282 minutes (range 250-310 minutes). The median estimated blood loss was $2595 \mathrm{ml}$ (range 1500-3200 $\mathrm{ml}$ ). All patients were followed up for 13-29 months, with a mean follow-up of 22 months. Adequate margins were achieved in 8 patients. Two patients $(20 \%)$ had a local relapse, including 1 patient with osteosarcoma with an adequate margin and 1 patient with Ewing's sarcoma with an inadequate margin (positive margin at pathological analysis). Local recurrence was detected in the surrounding soft tissue in 1 patient 

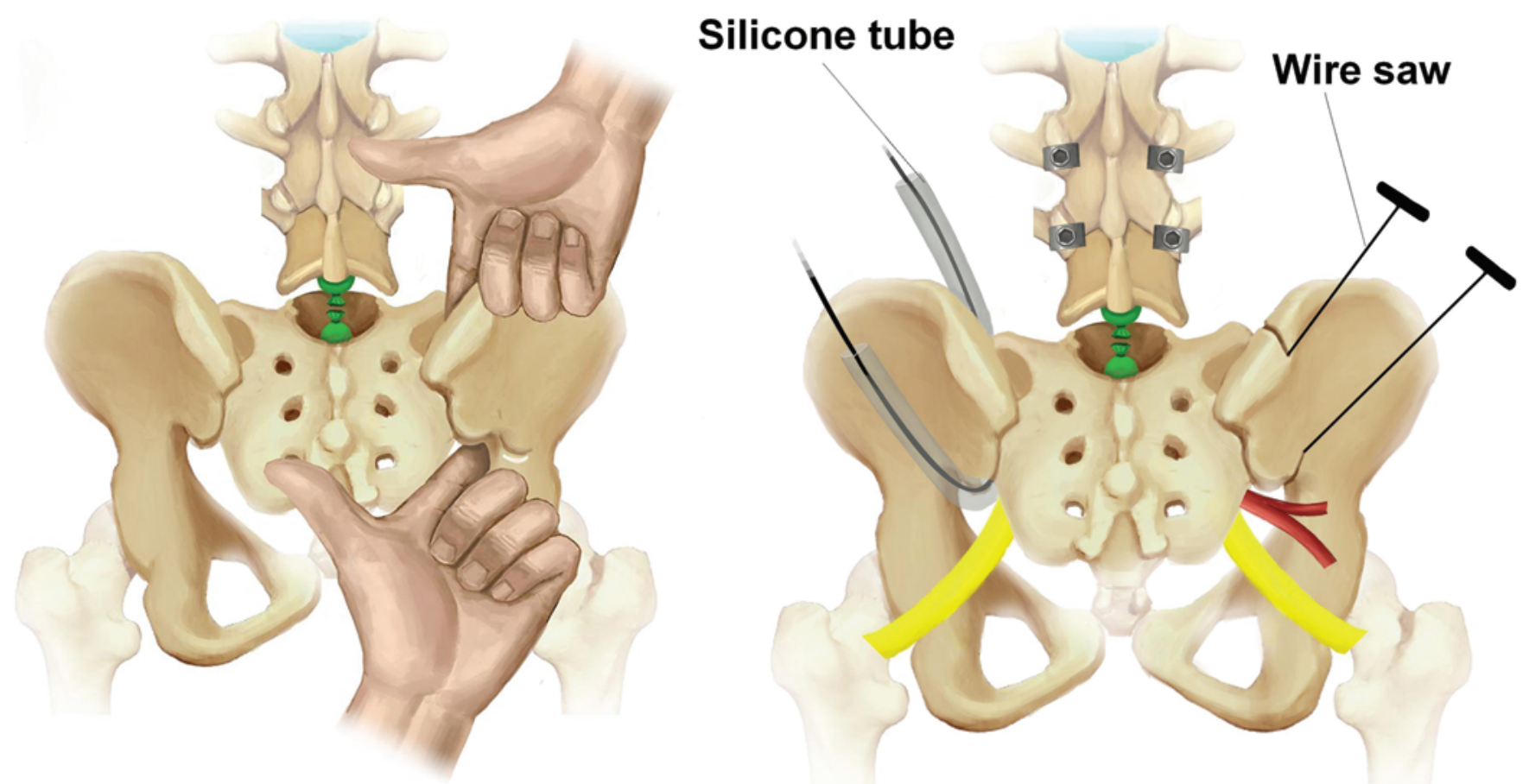

FIG. 1. Schematic diagrams of the operative procedure in total en bloc sacrectomy. Left: Blunt finger dissection from the upper and the lower edge of sacroiliac joint. Right: Placement of the silicone tube through the anterior space of the sacroiliac joint and the placement of the wire saw through the silicone tube. Copyright Wei Guo. Published with permission. Figure is available in color online only.

with Ewing's sarcoma 6 months after surgery, and in the surrounding soft tissue in 1 patient with osteosarcoma 10 months after surgery. The recurring lesion in the patient with osteosarcoma was resected adequately, and no further recurrence was detected at the last follow-up. How- ever, the patient died of a lung metastasis 18 months after surgery. The patient with Ewing's sarcoma who had local recurrence underwent local radiation therapy. The recurrent lesion continues to grow slowly and the patient is alive with disease as of the last follow-up. Lung metastasis was
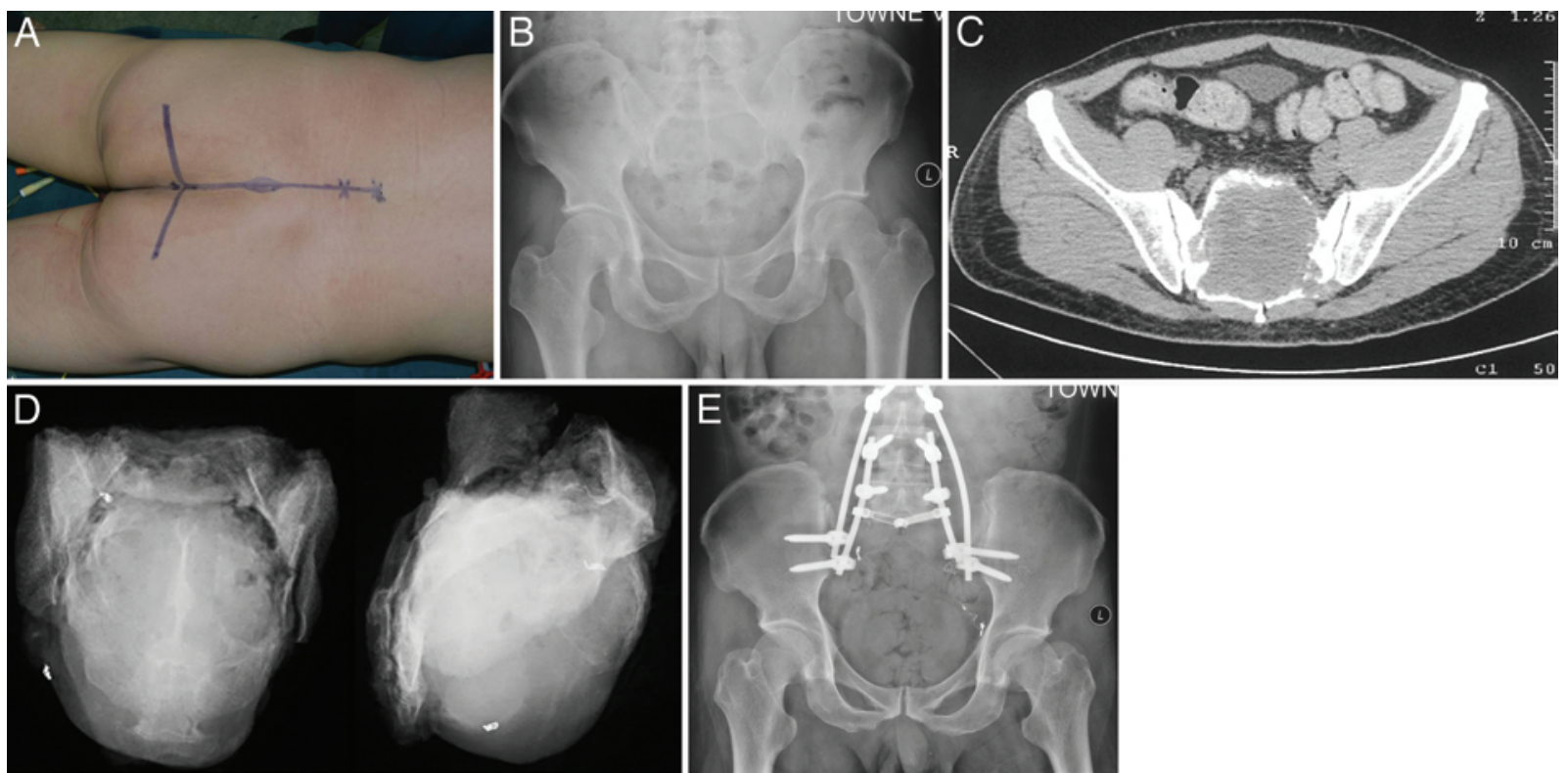

FIG. 2. Images obtained in a male patient with sacral malignant giant cell tumor involving $\$ 1-5$ that was treated with total sacrectomy. A: The patient was placed prone. An inverted $Y$ incision was made, and the biopsy track was removed along with the sacral tumor. B: Radiograph showing osteolysis in the sacrum. C: CT image of an osteolytic and expansible lesion of the sacrum. D: Removal of the entire sacrum. E: Radiograph showing reconstruction of lumbosacral stability after total sacrectomy. Figure is available in color online only. 
detected in 2 patients at last follow-up. Two patients died of disease (one with osteosarcoma and one with Ewing's sarcoma). One patient is alive with disease. Eight patients are alive without disease. Kaplan-Meier analysis estimated a 5-year overall survival rate of $70 \%$ for the 10 patients.

\section{Functional Results}

Among all 8 surviving patients, whose S1-5 sacral nerves were cut bilaterally, 7 patients could empty their bladder via catheterization and 1 patient by manually applying pressure to the abdominal wall at last follow-up. All patients experienced different degrees of constipation, but none required colostomy. Six patients could empty their bowels by using laxatives or enemas, and 2 could empty their bowels by manual removal of the stool. All 8 patients required diapers. Although the bilateral S-1 nerve roots of all 10 patients were cut during surgery, the function of the plantar flexion of ankle joint bilaterally was maintained in 9 patients. Of these, 3 patients had weak plantar flexion of the ankle joint bilaterally, and the remaining 6 patients had normal plantar flexion strength. In 1 patient with osteosarcoma, the right lumbosacral trunk was cut due to tumor involvement. The function of the right ankle joint was lost, but the function of the left ankle joint was maintained. At the last follow-up, among the 8 surviving patients, 6 were able to walk without assistive devices, and 2 were able to walk with external support.

\section{Complications}

Of the 10 patients, 4 had complications (total complication rate $40 \%$ ). Wound complications (deep infection and wound healing problems) occurred in 3 patients (30\%). One complication was minor complication and 3 were major. One patient had deep infection 2 months after surgery that was treated by debridement, drainage, and systemic antibiotics. The wound healed and the infection cleared. Two patients with wound healing problems were treated by debridement with eventual healing between 3 and 4 weeks. One patient had a distal deep vein thrombosis and was treated with anticoagulant drugs for 6 months with resolution. No mechanical breakdown was observed in any of the patients until the last follow-up.

\section{Discussion}

Most common primary malignant sacral tumors include chordoma, chondrosarcoma, and osteosarcoma, which are relatively resistant to radiotherapy. En bloc resection with an adequate margin is the only effective method for achieving long-term local control or cure. ${ }^{5,13,20,29,42,44}$ For patients with chordoma, which is the most common primary malignant sacral tumor, local tumor recurrence is highly correlated with the type of resection. With intralesional surgery, the local recurrence rate is as high as $83 \% .{ }^{6,44}$ Even when treated with a wide resection, however, the recurrence rate is high, ranging from $5 \%$ to $60 \%$. Of the 10 patients who underwent total sacrectomy in our series, 4 had a chordoma involving the sacrum, and no local recurrence after total sacrectomy was detected at the last follow-up. The high recurrence rate after wide resection may be due to contamination of the surgical incision or to satellite lesions that were not resected. Although the local control in the present study was satisfactory, the mean follow-up time was short and the number of patients was small compared with other studies. ${ }^{6,14,18}$ The local recurrence rate might be greater over a longer follow-up.

Ewing's sarcoma is considered radiation sensitive, but surgical advances and a growing awareness of the late effects of radiation, such as secondary malignancies, have increased the incidence of surgery, especially for resectable tumors. ${ }^{2,4,21,35}$ Combined analysis of 1058 patients with Ewing's sarcoma treated in the CESS81 (Cooperative Ewing's Sarcoma Study 81), CESS 86 (Cooperative Ewing's Sarcoma Study 86), and EICESS-92 (European Intergroup Cooperative Ewing's Sarcoma Study-92) trials revealed that the local control rate was significantly higher after surgery (with or without postoperative radiotherapy) than after radiotherapy alone $(92.5 \%$ vs $73.7 \%$, respectively; $p=0.001) .{ }^{34}$ Some authors reported that the 5 -year survival rate was higher for patients treated with chemotherapy and surgery (74\%-92\%) than for patients treated with chemotherapy and radiation therapy alone $(28 \%-60 \%) .3,26,30,33,41$ The lower survival rates reported with radiation therapy compared with surgery for local control may be related to residual nests of viable tumor tissue within the radiated site. ${ }^{24}$ Telles et al ${ }^{39}$ identified tumor tissue in 13 of 20 patients examined at autopsy, despite treatment with chemotherapy and radiation therapy. These residual nests of tumor tissue are potential sources of local recurrence or distant relapse. In the present study, 2 patients with Ewing's sarcoma were treated with surgery and chemotherapy. One patient had local recurrence and underwent local radiation therapy. The recurrent lesion continues to grow slowly and the patient is alive with disease as of the last follow-up. The other patient died of disease that developed after surgery. The sample size is too small and therefore has little statistical power. We believe that, with a larger number of cases, surgery will be shown to have significant advantages for local control in patients with Ewing's sarcoma.

Three major problems must be addressed by the surgeon before total en bloc sacrectomy via a posterior-only approach can be performed: 1) performing an osteotomy through the ilium without injuring the bilateral iliac vessels, lumbosacral trunk, and viscera; 2) mobilizing the bilateral internal iliac vessels from the sacrum, and the soft-tissue anterior to the tumor; and 3) removing the L5-S1 disc without injuring the adjacent vital vessels attached tightly to the L-5 vertebral body. All 10 patients in the present group underwent total sacrectomy via the posterior-only approach. Only 4 previous reports have specifically addressed total en bloc sacrectomy using the posterior-only approach (Table 2). In the current study, the method for osteotomy of the ilium bilaterally differed from the previously reported methods. In the previous studies, a chisel, ${ }^{1}$ oscillating saw,${ }^{40}$ and high-speed bur ${ }^{9,25}$ were used to cut the ilium on both sides. These methods for osteotomy were performed from the outer aspect to the inner aspect of the ilium, which may injure bilateral iliac vessels and the lumbosacral trunk. In our series, osteotomy of the ilium was safely performed using a wire saw introduced through the anterior aspect of the sacroiliac joint, and it started from the inner aspect to the outer aspect of the ilium. Before the osteotomy of the ilium on 
TABLE 2. Comparison of the literature about total en bloc sacrectomy via posterior-only approach

\begin{tabular}{|c|c|c|c|c|c|c|c|}
\hline Authors \& Year & $\begin{array}{l}\text { No. of } \\
\text { Patients }\end{array}$ & $\begin{array}{c}\text { Mean Op } \\
\text { Duration (mins) }\end{array}$ & $\begin{array}{l}\text { Tools Used for } \\
\text { Lateral Iliac } \\
\text { Osteotomy }\end{array}$ & $\begin{array}{l}\text { Mean Blood } \\
\text { Loss (ml) }\end{array}$ & $\begin{array}{l}\text { Methods Used to } \\
\text { Reduce Bleeding }\end{array}$ & $\begin{array}{l}\text { Mean Follow-Up } \\
\text { Time (mos) }\end{array}$ & $\begin{array}{l}\text { Complication \& } \\
\text { Oncological Outcome } \\
\text { (no. of patients) }\end{array}$ \\
\hline Current study & 10 & $\begin{array}{l}282 \text { (range } \\
250-310)\end{array}$ & Wire saw & $\begin{array}{l}2595 \text { (range } \\
1500-3200 \text { ) }\end{array}$ & $\begin{array}{l}\text { Angiographic emboli- } \\
\text { zation; aortic bal- } \\
\text { loon }\end{array}$ & 22 (range 13-29) & $\begin{array}{l}\text { Wound infection (1); } \\
\text { wound healing prob- } \\
\text { lems (2); local recur- } \\
\text { rence (2); lung meta- } \\
\text { stases (2) }\end{array}$ \\
\hline $\begin{array}{l}\text { McLoughlin et al., } \\
2008\end{array}$ & 1 & NR & High-speed bur & 6000 & $\begin{array}{l}\text { Ligation of internal } \\
\text { iliac vessels }\end{array}$ & 24 & None \\
\hline $\begin{array}{l}\text { Varga \& Lazary, } \\
2010\end{array}$ & 1 & NR & Oscillating saw & NR & None & NR & None \\
\hline $\begin{array}{l}\text { Asavamongkolkul } \\
\text { \& Waikakul, } \\
2012^{*}\end{array}$ & 21 & $\begin{array}{l}384 \text { (range } \\
300-600)\end{array}$ & Osteotome & $\begin{array}{l}1238 \text { (range } \\
850-1650 \text { ) }\end{array}$ & Bone wax & 84 & $\begin{array}{l}\text { Wound infection (2); lo- } \\
\text { cal recurrence (3); } \\
\text { metastases (1) }\end{array}$ \\
\hline $\begin{array}{l}\text { Clarke et al., } \\
2012 \dagger\end{array}$ & 36 & NR & High-speed bur & NR & $\begin{array}{l}\text { Angiographic embo- } \\
\text { lization }\end{array}$ & 47.3 (range 12-86) & $\begin{array}{l}\text { Wound-related problems } \\
\text { (9); local recurrence \& } \\
\text { metastases (6) }\end{array}$ \\
\hline
\end{tabular}

$\mathrm{NR}=$ not reported

* Nine patients with subtotal sacrectomy were included.

$\dagger$ Thirty-four patients with subtotal sacrectomy were included.

both sides, gauze was packed into the space in front of the anterior aspect of the bilateral sacroiliac joints to avoid injuring the internal iliac vessels and lumbosacral trunks. Using a saw to cut off the iliac bone is much more effective than a chisel, which may destroy the integrity of the tumor, and the cutting margin is neat. After osteotomy of the ilium bilaterally, the sacrum was mobilized. The internal iliac vessels and presacral soft tissue were easily dissected from the sacrum and tumor, and the remaining part of the L5-S1 disc was removed without injuring the adjacent vital vessels attached tightly to the L-5 vertebral body through a bilateral anterolateral approach by lifting the sacrum posteriorly.

Sacral tumors are difficult to treat due to massive intraoperative blood loss. Many authors have reported a mean intraoperative blood loss greater than $6000 \mathrm{ml}$, making it difficult to achieve wide resection due to an obstructed view, and leading to hemorrhagic shock and death. . $^{14,25,28,32}$ Preoperative selective embolization of sacral tumors has proved to be an effective method for minimizing intraoperative blood loss, which will improve the safety of the operation and the resectability of sacral tumors. ${ }^{27,43} \mathrm{We}$ also applied an aortic balloon to decrease intraoperative blood loss, by inserting it into the abdominal artery via femoral access. This technique was not used in the previous reports (Table 2). With this technique, the operative field is more clearly exposed, allowing the surgeons to more easily dissect the sacral tumor away from the surrounding tissue and widely resect the tumor. In the present study, both preoperative embolization and aortic balloon insertion were performed for all 10 patients who underwent total en bloc sacrectomy. The mean blood loss was $2595 \mathrm{ml}$, and none of the patients died of hemorrhagic shock. Sacral tumors in our series were resected with adequate margins in 8 patients. No tumor rupture occurred, and no viscera or great vessels in the pelvis were injured during the surgery.
Reconstruction of the integrity of the pelvic wing after resection of the sacrum is performed using various methods,${ }^{10,16,44}$ but all of the reconstruction methods used to stabilize the sacroiliac joints and restore the integrity of the lumbar spine and pelvis generally involve bone grafts and internal fixation with various screws and steel plates. To reduce postoperative complications caused by long-term bed rest and promote earlier walking, all 10 patients underwent lumbar spine and iliac bone fixation with rods and pedicle screws. Reconstruction with internal fixation may facilitate early mobilization and allow patients to walk sooner. Muscles and scar tissue between the pelvis and the spine form a biological sling and eventually stabilize the spine. ${ }^{11,42}$ At this point, to minimize the surgical duration, bone grafting was not performed in most of the patients. Only 3 patients underwent fibular grafting for bone reconstruction.

Bladder and bowel function are disturbed if all sacral nerves are cut during the total en bloc sacrectomy. ${ }^{7,37,42}$ The detrusor function of the bladder is lost and the patient must depend on the abdominal muscles and manual pressure for voluntary voiding. If the bladder is not emptied adequately using these techniques, catheterization is necessary. Complete loss of external anal sphincter function and anorectal sensation lead to loss of sensitivity and stimulus to defecate. Patients must use laxatives or enemas to empty their bowels periodically and wear diapers. In our study, among the 8 surviving patients, 7 patients could empty their bladders by catheterization and one patient by applying manual pressure to the abdominal wall at the last follow-up. Six patients could empty their bowels using laxatives or enemas, whereas 2 had to manually remove the stool. All 8 patients required diapers. Although the gastrocnemius and soleus muscles receive the most innervation by S-1 and S-2, relatively good motor function is possible after cutting the sacral nerves. Innervation by L-5 may suffice 
TABLE 3. Comparison of the literature about wound complication after sacral tumor resection

\begin{tabular}{|c|c|c|c|c|}
\hline Authors \& Year & $\begin{array}{l}\text { No. of } \\
\text { Patients }\end{array}$ & Complication Rate & Management of Complications & Risk Factor \\
\hline Current study & 10 & $\begin{array}{l}\text { SSI rate } 10 \%(1 / 10) ; \text { wound healing } \\
\text { problems rate } 20 \%(2 / 10)\end{array}$ & Debridement \& antibiotics & NA \\
\hline Zileli et al., 2003 & 34 & $\begin{array}{l}\text { SSI \& wound dehiscence rate } 14.7 \% \\
\quad(5 / 34)\end{array}$ & Dressings, debridement, \& antibiotics & NA \\
\hline Sciubba et al., 2008 & 46 & SSI rate $39 \%(18 / 46)$ & Debridement \& antibiotics & $\begin{array}{l}\text { Previous lumbosacral surgery, no. of } \\
\text { surgeons scrubbed in }\end{array}$ \\
\hline Chen et al., 2011 & 45 & SSI rate $35.6 \%(16 / 45)$ & $\begin{array}{l}\text { Debridement, antibiotics, \& removal of } \\
\text { instrumentation }\end{array}$ & Albumin level, op time \\
\hline Ruggieri et al., 2012 & 82 & SSI rate $28 \%(23 / 82)$ & Debridement \& antibiotics & Type of op \& op duration \\
\hline Li et al., 2013 & 387 & $\begin{array}{l}\text { SSI rate } 13.2 \%(51 / 387) \text { \& dehiscence } \\
\quad 16 \%(62 / 387)\end{array}$ & $\begin{array}{l}\text { Debridement, antibiotics, \& removal of } \\
\text { instrumentation }\end{array}$ & $\begin{array}{l}\text { Age (>40 yrs), diabetes mellitus, pre- } \\
\text { vious radiation, max tumor diame- } \\
\text { ter, instrumentation used, rectum } \\
\text { rupture, CSF leakage }\end{array}$ \\
\hline
\end{tabular}

$\mathrm{NA}=$ not available $; \mathrm{SSI}=$ surgical site infection .

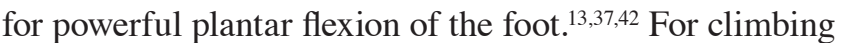
stairs, active extension of the hip is difficult due to partial loss of function of the gluteus maximus muscle. Hypertrophy of the hamstrings and the adductor magnus muscle may partially compensate for this loss. ${ }^{37,42}$ In the present study, plantar flexion of the ankle joint bilaterally was maintained in 9 patients whose L-5 nerve roots were preserved bilaterally. In 1 patient with osteosarcoma, the right lumbosacral trunk (L-4 and L-5) was cut due to tumor involvement and the function of the right ankle joint was lost. At the last follow-up, among the 8 surviving patients, 6 were able to walk without assistive devices, and 2 were able to walk with external support.

The reported rate of wound complications after sacrectomy is between $14.7 \%$ and $39 \% \%^{8,22,31,36,46}$ (Table 3 ). In 2003, Zileli et al. presented the results of 34 patients who underwent sacrectomy and reported a wound complication rate of $14.7 \% .{ }^{46}$ In 2013 , Li et al. presented a study of 387 patients who underwent sacrectomy and reported a wound complication rate of $29.2 \% .^{22}$ Many factors influence this rate, including previous lumbosacral surgery, number of surgeons scrubbed in, low albumin level, type of surgery, prolonged operation time, older age ( $>40$ years), diabetes mellitus, previous radiation therapy, large tumor size, rectum rupture, CSF leakage, wide surgical exposure, proximity of the anus, presence of a huge dead space after sacrectomy, poor blood supply to the skin flap, and the use of instrumentation..$^{8,9,22,31,36,42,46}$ For patients undergoing total sacrectomy, the wound complication rate would be higher due to a longer operation time, wider surgical exposure, and larger tumor size. In 2000, Wuisman et al. reported that the wound complication rate for patients who underwent total sacrectomy was $45.5 \% .^{42}$ In our series, the rate of these complications (wound healing problems and wound infections) was $30 \%$ (3 of 10); this lower rate may be due to the relatively short operative time (mean 282 minutes; range 250-310 minutes), no cases of rectum rupture and CSF leakage, and adequate blood supply to the skin flap. In the present study, by not ligating the internal iliac arteries bilaterally, we ensured an adequate blood supply to the gluteus maximus skin flap.

\section{Conclusions}

Total en bloc sacrectomy using a posterior-only approach is feasible and safe in selected patients, and is an important procedure for the treatment of primary malignant tumor involving the entire sacrum or only the top portion.

\section{References}

1. Asavamongkolkul A, Waikakul S: Wide resection of sacral chordoma via a posterior approach. Int Orthop 36:607-612, 2012

2. Bacci G, Longhi A, Briccoli A, Bertoni F, Versari M, Picci P: The role of surgical margins in treatment of Ewing's sarcoma family tumors: experience of a single institution with 512 patients treated with adjuvant and neoadjuvant chemotherapy. Int J Radiat Oncol Biol Phys 65:766-772, 2006

3. Bacci G, Toni A, Avella M, Manfrini M, Sudanese A, Ciaroni D, et al: Long-term results in 144 localized Ewing's sarcoma patients treated with combined therapy. Cancer 63:14771486, 1989

4. Balamuth NJ, Womer RB: Ewing's sarcoma. Lancet Oncol 11:184-192, 2010

5. Bergh P, Gunterberg B, Meis-Kindblom JM, Kindblom LG: Prognostic factors and outcome of pelvic, sacral, and spinal chondrosarcomas: a center-based study of 69 cases. Cancer 91:1201-1212, 2001

6. Bergh P, Kindblom LG, Gunterberg B, Remotti F, Ryd W, Meis-Kindblom JM: Prognostic factors in chordoma of the sacrum and mobile spine: a study of 39 patients. Cancer 88:2122-2134, 2000

7. Biagini R, Ruggieri P, Mercuri M, Capanna R, Briccoli A, Perin S, et al: Neurologic deficit after resection of the sacrum. Chir Organi Mov 82:357-372, 1997

8. Chen KW, Yang HL, Lu J, Wang GL, Ji YM, Bao ZH, et al: Risk factors for postoperative wound infections of sacral chordoma after surgical excision. J Spinal Disord Tech 24:230-234, 2011

9. Clarke MJ, Dasenbrock H, Bydon A, Sciubba DM, McGirt MJ, Hsieh PC, et al: Posterior-only approach for en bloc sacrectomy: clinical outcomes in 36 consecutive patients. Neurosurgery 71:357-364, 2012

10. Dickey ID, Hugate RR Jr, Fuchs B, Yaszemski MJ, Sim FH: Reconstruction after total sacrectomy: early experience with a new surgical technique. Clin Orthop Relat Res 438:4250,2005 
11. Doita M, Harada T, Iguchi T, Sumi M, Sha H, Yoshiya S, et al: Total sacrectomy and reconstruction for sacral tumors. Spine (Phila Pa 1976) 28:E296-E301, 2003

12. Enneking WF: A system of staging musculoskeletal neoplasms. Clin Orthop Relat Res (204):9-24, 1986

13. Fourney DR, Rhines LD, Hentschel SJ, Skibber JM, Wolinsky JP, Weber KL, et al: En bloc resection of primary sacral tumors: classification of surgical approaches and outcome. J Neurosurg Spine 3:111-122, 2005

14. Fuchs B, Dickey ID, Yaszemski MJ, Inwards CY, Sim FH: Operative management of sacral chordoma. J Bone Joint Surg Am 87:2211-2216, 2005

15. Gallia GL, Haque R, Garonzik I, Witham TF, Khavkin YA, Wolinsky JP, et al: Spinal pelvic reconstruction after total sacrectomy for en bloc resection of a giant sacral chordoma. Technical note. J Neurosurg Spine 3:501-506, 2005

16. Gokaslan ZL, Romsdahl MM, Kroll SS, Walsh GL, Gillis TA, Wildrick DM, et al: Total sacrectomy and Galveston Lrod reconstruction for malignant neoplasms. Technical note. J Neurosurg 87:781-787, 1997

17. Guo W, Tang X, Zang J, Ji T: One-stage total en bloc sacrectomy: a novel technique and report of 9 cases. Spine (Phila Pa 1976) 38:E626-E631, 2013

18. Hanna SA, Aston WJ, Briggs TW, Cannon SR, Saifuddin A: Sacral chordoma: can local recurrence after sacrectomy be predicted? Clin Orthop Relat Res 466:2217-2223, 2008

19. Hsieh PC, Xu R, Sciubba DM, McGirt MJ, Nelson C, Witham TF, et al: Long-term clinical outcomes following en bloc resections for sacral chordomas and chondrosarcomas: a series of twenty consecutive patients. Spine (Phila Pa 1976) 34:2233-2239, 2009

20. Huth JF, Dawson EG, Eilber FR: Abdominosacral resection for malignant tumors of the sacrum. Am J Surg 148:157161,1984

21. Indelicato DJ, Keole SR, Shahlaee AH, Shi W, Morris CG, Marcus RB Jr: Definitive radiotherapy for ewing tumors of extremities and pelvis: long-term disease control, limb function, and treatment toxicity. Int J Radiat Oncol Biol Phys 72:871-877, 2008

22. Li D, Guo W, Qu H, Yang R, Tang X, Yan T, et al: Experience with wound complications after surgery for sacral tumors. Eur Spine J 22:2069-2076, 2013

23. Li D, Guo W, Tang X, Ji T, Zhang Y: Surgical classification of different types of en bloc resection for primary malignant sacral tumors. Eur Spine J 20:2275-2281, 2011

24. Marco RA, Gentry JB, Rhines LD, Lewis VO, Wolinski JP, Jaffe N, et al: Ewing's sarcoma of the mobile spine. Spine (Phila Pa 1976) 30:769-773, 2005

25. McLoughlin GS, Sciubba DM, Suk I, Witham T, Bydon A, Gokaslan ZL, et al: En bloc total sacrectomy performed in a single stage through a posterior approach. Neurosurgery 63 (1 Suppl 1):ONS115-ONS120, 2008

26. Nesbit ME Jr, Gehan EA, Burgert EO Jr, Vietti TJ, Cangir A, Tefft M, et al: Multimodal therapy for the management of primary, nonmetastatic Ewing's sarcoma of bone: a longterm follow-up of the First Intergroup study. J Clin Oncol 8:1664-1674, 1990

27. Prabhu VC, Bilsky MH, Jambhekar K, Panageas KS, Boland PJ, Lis E, et al: Results of preoperative embolization for metastatic spinal neoplasms. J Neurosurg 98 (2 Suppl):156-164, 2003

28. Puri A, Agarwal MG, Shah M, Srinivas CH, Shukla PJ, Shrikhande SV, et al: Decision making in primary sacral tumors. Spine J 9:396-403, 2009

29. Raque GH Jr, Vitaz TW, Shields CB: Treatment of neoplastic diseases of the sacrum. J Surg Oncol 76:301-307, 2001

30. Rosen G, Caparros B, Nirenberg A, Marcove RC, Huvos AG, Kosloff C, et al: Ewing's sarcoma: ten-year experience with adjuvant chemotherapy. Cancer 47:2204-2213, 1981
31. Ruggieri P, Angelini A, Pala E, Mercuri M: Infections in surgery of primary tumors of the sacrum. Spine (Phila Pa 1976) $37: 420-428,2012$

32. Sahakitrungruang C, Chantra K, Dusitanond N, Atittharnsakul P, Rojanasakul A: Sacrectomy for primary sacral tumors. Dis Colon Rectum 52:913-918, 2009

33. Sailer SL, Harmon DC, Mankin HJ, Truman JT, Suit HD: Ewing's sarcoma: surgical resection as a prognostic factor. Int J Radiat Oncol Biol Phys 15:43-52, 1988

34. Schuck A, Ahrens S, Paulussen M, Kuhlen M, Könemann S, Rübe C, et al: Local therapy in localized Ewing tumors: results of 1058 patients treated in the CESS 81, CESS 86, and EICESS 92 trials. Int J Radiat Oncol Biol Phys 55:168-177, 2003

35. Schuck A, Ahrens S, von Schorlemer I, Kuhlen M, Paulussen M, Hunold A, et al: Radiotherapy in Ewing tumors of the vertebrae: treatment results and local relapse analysis of the CESS 81/86 and EICESS 92 trials. Int J Radiat Oncol Biol Phys 63:1562-1567, 2005

36. Sciubba DM, Nelson C, Gok B, McGirt MJ, McLoughlin GS, Noggle JC, et al: Evaluation of factors associated with postoperative infection following sacral tumor resection. J Neurosurg Spine 9:593-599, 2008

37. Stener B, Gunterberg B: High amputation of the sacrum for extirpation of tumors. Principles and technique. Spine (Phila Pa 1976) 3:351-366, 1978

38. Tang X, Guo W, Yang R, Tang S, Dong S: Use of aortic balloon occlusion to decrease blood loss during sacral tumor resection. J Bone Joint Surg Am 92:1747-1753, 2010

39. Telles NC, Rabson AS, Pomeroy TC: Ewing's sarcoma: an autopsy study. Cancer 41:2321-2329, 1978

40. Varga PP, Lazary A: Chordoma of the sacrum: "en bloc" total sacrectomy and lumbopelvic reconstruction. Eur Spine J 19:1039-1040, 2010

41. Wilkins RM, Pritchard DJ, Burgert EO Jr, Unni KK: Ewing's sarcoma of bone. Experience with 140 patients. Cancer 58:2551-2555, 1986

42. Wuisman P, Lieshout O, Sugihara S, van Dijk M: Total sacrectomy and reconstruction: oncologic and functional outcome. Clin Orthop Relat Res (381): 192-203, 2000

43. Yang HL, Chen KW, Wang GL, Lu J, Ji YM, Liu JY, et al: Pre-operative transarterial embolization for treatment of primary sacral tumors. J Clin Neurosci 17:1280-1285, 2010

44. York JE, Kaczaraj A, Abi-Said D, Fuller GN, Skibber JM, Janjan NA, et al: Sacral chordoma: 40-year experience at a major cancer center. Neurosurgery 44:74-80, 1999

45. Zhang HY, Thongtrangan I, Balabhadra RS, Murovic JA, Kim DH: Surgical techniques for total sacrectomy and spinopelvic reconstruction. Neurosurg Focus 15(2):E5, 2003

46. Zileli M, Hoscoskun C, Brastianos P, Sabah D: Surgical treatment of primary sacral tumors: complications associated with sacrectomy. Neurosurg Focus 15(5):E9, 2003

\section{Author Contributions}

Conception and design: Guo, Zang. Acquisition of data: Zang. Analysis and interpretation of data: Zang, Li. Drafting the article: Zang. Critically revising the article: all authors. Reviewed submitted version of manuscript: Guo. Approved the final version of the manuscript on behalf of all authors: Guo. Statistical analysis: Zang. Administrative/technical/material support: Guo, Yang, Tang. Study supervision: Guo.

\section{Correspondence}

Wei Guo, Xizhimen South St. \#11, People's Hospital, Peking University, Beijing, China 100044. email: bonetumor@163.com. 